\title{
Who Adopts the Airbnb Innovation? An Analysis of International Visitors to Western Australia
}

\author{
Michael Volgger, Christof Pforr, Agnieszka Elzbieta Stawinoga, Ross Taplin and Steve Matthews*
}

\author{
Dr Michael Volgger \\ School of Marketing (Tourism Research Cluster), Curtin Business School, Curtin University, \\ Australia \\ Catholic University of Eichstätt-Ingolstadt, Germany \\ Eurac Research, Institute for Regional Development, Italy \\ Address: GPO Box U1987 \\ 6845 Perth, Western Australia, Australia \\ Email: michael.volgger@curtin.edu.au \\ Phone: +61 892664620 \\ (corresponding author) \\ A/Prof Christof Pforr \\ School of Marketing (Tourism Research Cluster), Curtin Business School, Curtin University, \\ Australia \\ Address: GPO Box U1987 \\ 6845 Perth, Western Australia, Australia \\ Email: c.pforr@curtin.edu.au \\ Phone: +61892667743 \\ Dr Agnieszka Elzbieta Stawinoga \\ Eurac Research, Institute for Regional Development, Italy \\ Address: Viale Druso 1, I-39100 Bolzano \\ Email: agnieszka.stawinoga@eurac.edu \\ Phone: +390471055017 \\ Prof Ross Taplin \\ School of Accounting (Tourism Research Cluster), Curtin Business School, Curtin University, \\ Australia \\ Address: GPO Box U1987 \\ 6845 Perth, Western Australia, Australia \\ Email: r.taplin@,curtin.edu.au \\ Phone: +61892663033
}

\footnotetext{
${ }^{*}$ This is an author generated postprint version (with author's formatting) of the article:

Volgger, M., Pforr, C., Stawinoga, A., Taplin, R., \& Matthews, S. (2018). Who adopts the Airbnb innovation? An analysis of international visitors to Western Australia. Tourism Recreation Research, 43 (3), 305-320.
}

The final publication is available at https://doi.org/10.1080/02508281.2018.1443052 
Steve Matthews

Tourism Research Australia

Address: GPO Box 2386

Email: Steve.Matthews@tra.gov.au

Phone: +61262726887

\section{Conflict of interest}

None

\section{Funding acknowledgements}

This work was supported by the Bankwest Curtin Economics Centre (BCEC), Tourism Western Australia and the Government of Western Australia-Department of the Premier and Cabinet (Dr Kylie Coulson). 


\title{
Who Adopts the Airbnb Innovation? An Analysis of International
}

\author{
Visitors to Western Australia
}

\begin{abstract}
Airbnb is the most prominent example of novel peer-to-peer networks in tourism. This new form of accommodation provision may alter demand structures in tourism destinations and has led to uncertainty amongst established accommodation providers and destination marketers. To gain a better understanding of Airbnb adopters, this paper systematically compares actual travel behaviour of Airbnb users in a specific destination with that of visitors staying in traditional accommodation. Due to this controlled comparison, the paper is the first one to offer a robust comparative profiling of Airbnb users. The analysis is based on a logistic regression of data from the standardized International Visitor Survey for 2015 in Western Australia. Results indicate that Airbnb users in Western Australia differ from visitors staying in traditional accommodation, but that it might be wrong to conceive Airbnb adopters to be "alternative tourists" beyond the mainstream.
\end{abstract}

\section{Keywords}

Airbnb; sharing economy; innovation; adoption; profiling 


\section{Introduction}

The peer-to-peer online platform Airbnb enables professional or private owners or tenants of houses, apartments and spare rooms to offer their premises to visitors for short-term rentals. Like few other recent developments in tourism, Airbnb is associated with disruptive innovation (Gutting, 2015; Karlsson, Kemperman, \& Dolnicar, 2017; Sigala, 2017). The platform has seen exponential growth patterns over the first ten years of its existence and is impacting on the tourism industry globally as well as locally (Airbnb, 2017a; Karlsson et al., 2017). This allows Airbnb to report that by now it has "more listings than the top three hotel chains combined" (Airbnb Citizen, 2017), although there are obviously significant differences in ownership compared to traditional accommodation supply. This growth has repeatedly and increasingly raised questions as to an appropriate response to the Airbnb phenomenon (Dredge \& Gyimóthy, 2015 ) in light of its potential impacts on housing and the rental market, income and taxation implications and also its potential effects on the tourism sector (Fang, Ye, \& Law, 2016).

The impressive growth of the Airbnb phenomenon has created uncertainties among traditional providers in the accommodation sector. These established stakeholders sometimes voice concerns about uneven playing fields (Heo, 2016; Oskam \& Boswijk, 2016) based on the assumption that Airbnb directly competes for the same pool of visitors, although previous studies do not come to unanimous results. Some point to partial substitution effects (Zervas, Proserpio, \& Byers, 2016), others see little impact on large accommodation providers (Varma et al., 2016). In essence, the current discourse spans from whether Airbnb expands the market size of the tourism economy for the benefit of all to whether it just shifts business from traditional actors to emerging ones, and is thus an expression of forces of "creative destruction" (Schumpeter, 1942). As a contribution to this debate, researchers call for more comprehensive studies to capture the 
impact of Airbnb on tourism demand (Heo, 2016) and to learn more about the types of visitors it attracts (Lawler, 2012).

It is widely acknowledged that participating in the sharing economy as a visitor entails benefits (e.g. lower costs, convenience, experience) but also risks (e.g. quality, safety, security). It is therefore of interest to profile these visitors systematically (Sigala, 2017). Some scholars argue that a particular type of demand, partly linked to segments with lower price tolerance, can be satisfied (Fang et al., 2016; Pizam, 2014). However, the argument of particularity does not exclusively go along the lines of price and budget, but considers experiential aspects around notions of authenticity as equally important. Airbnb propagates itself as a "[p]latform to have affordable, authentic experiences" (Airbnb Citizen, 2017), alluding to notions of "alternative tourism" that had previously been used to describe other networking technology based accommodation forms such as couchsurfing (Molz, 2013). Therefore, an implicitly or explicitly held common assumption regarding Airbnb use is that it attracts visitors with different travel behaviour than those seen in mainstream tourism.

While such assumptions are commonly made, and some generic ad-hoc surveys on intention to use or not use Airbnb have been conducted (Poon \& Huang, 2017), to the best of our knowledge no independent study exists to date that systematically compares in a controlled fashion actual travel behaviour of Airbnb users in a particular destination with that of visitors staying in traditional accommodation. It is largely unclear whether Airbnb users form a particular visitor group after all - and if so, what the particularity specifically entails. To close this gap and embracing the idea that Airbnb is a somewhat new phenomenon to the tourism industry — as is evidenced by a growing but still moderate market penetration (demand shares around 3 to $4 \%$ in many markets in 2016, but growing mostly at yearly rates well beyond 30\%, see STR, 2017)—, 
the purpose of this paper is to investigate if and what differentiates those who adopt the Airbnb innovation from those who do not, by comparing actual trip behaviour and personal characteristics of international Airbnb users in Western Australia with Airbnb non-users. Therefore, by performing a demand side-based profiling, this work contributes to informing marketers about the typical Airbnb user and about the extent to which Airbnb users constitute a specific segment of visitors.

\section{Literature Review}

\subsection{Airbnb as a New Phenomenon in the Tourism Industry}

While there is nothing new in principle to the hybrid forms of exchange, distribution, production and of cultivating relationships denominated "sharing", the specific phenomenon of the so-called "sharing economy" is closely tied to the introduction of internet platforms (Belk, 2014; John, 2013). This peer-to-peer sharing, which has many similarities with a trading of access-rights between individuals, is facilitated by both not-for-profit as well as profit-based online platform providers (such as Airbnb). In contrast to traditional sharing, the "pseudo sharing" of the sharing economy is rarely free (Belk, 2014). In any case, tourism is among the most affected sectors (Heo, 2016). While sometimes criticized for its commodification of previously non-monetized services and for separating risk from reward (Slee, 2015), for its associated power imbalances and alleged power accumulation in the hands of intermediaries (Dredge \& Gyimóthy, 2015) and for its operation in regulatory gaps leading in the view of some to "unfair competition" (Oskam \& Boswijk, 2016), the sharing economy within the tourism industry has grown at a rate and has 
created impacts of a type that are typical for disruptive phenomena (Bridges \& Vásquez, 2016; Christensen, 2006; Guttentag, 2015).

Airbnb, a sharing economy platform for the (short-term) exchange of rooms and apartments for a fee, has only been founded in 2008. After experiencing years of exponential growth on a worldwide scale, according to its own reports, Airbnb has more than 3 million listings and hosted almost 80 million people in 2016 (Airbnb, 2017a; Airbnb Citizen, 2017). For instance, Paris registered more than 50,000 Airbnb listings in that year, the highest number of any city (Cox, 2016).

The novelty of the sharing economy phenomena and especially of Airbnb led to several studies focusing on the impact of these innovations in tourism. For instance, Fang et al. (2016) present some macroeconomic evidence that the entry of Airbnb is positively associated with the overall employment level in the tourism industry; however, they also note a decrease in the positive marginal effect with a rise in the number of Airbnb listings. While claiming distinctive qualities of Airbnb type of supply, Zervas et al. (2016) find a partial substitution effect, which in the case of holiday-travel-focused lower-end hotels in Texas allows associating an increase in Airbnb listings with a decrease in hotel room revenues. The higher probability of substitution with low-end accommodation types is confirmed by visitor statements in other destinations (Guttentag \& Smith, 2017; Hajibaba \& Dolnicar, 2017; Koh \& King, 2017). Similarly, interviews with accommodation providers suggest that major providers are less worried than small and mid-sized ones (Varma et al., 2016). In contrast, recent studies find substitution effects irrespective of hotels' quality attributes, and rather highlight the moderating role of price (Xie \& Kwok, 2017). Given the lowering of market entry barriers, other studies speculate about the 
impact of Airbnb and similar sharing economy phenomena on local residents' attitudes towards tourism (Heo, 2016).

Besides such macroscopic analyses of net effects, more fine-grain and methodologically individualistic consumer behaviour perspectives were employed to first assist in a better understanding of Airbnb users before inferring aggregate, macro-economic effects. Amongst others, it is argued that Airbnb usage is driven by lower costs, by the possibility to generate particular experiences, by the possibility to obtain "community" experiences and foster social interactions or even ecological and social sustainability (Guttentag, 2015; Heo, 2016; Mody, Suess, \& Lehto, 2017; Panda, Verma, \& Mehta, 2015; Tussyadiah \& Pesonen, 2016). Such different consumer behaviour is triggered by some relatively unique product components Airbnb offers. For example, Airbnb is innovative in the broad range and quite unstandardized accommodation options made available, including different types — such as shared rooms, shared apartments and whole apartments or diversely styled houses (including castles, tents and boats) - and atypical places, which cater to consumers' wants for idiosyncratic differentiation and uniqueness (Liu \& Mattila, 2017). Airbnb is also innovative in its promotion of direct exchange between the visitor and the host ("peer-to-peer") (Karlsson et al., 2017), which might trigger feelings of belongingness in consumers (Liu \& Mattila, 2017). The relevance of novelty seeking and belongingness/interaction were, next to money saving, confirmed to be key building blocks of motivational clusters in Airbnb users (Guttentag, Smith, Potwarka, \& Havitz, 2017). To summarise, Airbnb's short-term accommodation offer blurs established boundaries of holiday accommodation and structurally bridges traditional housing and typical tourism accommodation allowing for a new variety and perceived authenticity of tourism accommodation. 
This study takes a similar stance to the above fine-grain behavioural approaches, but in contrast to its predecessors, analyses Airbnb users more systematically and from an innovation adoption perspective. While first descriptive studies or ad-hoc surveys that compare people who intend to use Airbnb with those who do not were published (Poon \& Huang, 2017; Varma et al., 2016), this study is the first to our knowledge that offers a systematic, inferential analysis (based on a relatively consistent sample size) on the differences in actual travel behaviour between Airbnb users and non-users, within the context of a specific destination.

\subsection{Innovation Adoption: Acceptance of New Products and Services}

To understand the impact of new web-based services such as Airbnb, innovation diffusion research provides useful lenses (Peres, Muller, \& Mahajan, 2010). Innovation includes both the invention and the successful introduction of inventions into the market. This means that it is constitutive for innovative products and services that customers accept them (Van den Bulte \& Stremersch, 2004). This process of acceptance and propagation of innovations can, amongst others, be analysed from the micro-perspective of the individual and its decision making whether to adopt or not adopt a new good or service. Consumer-related, product-related and market/culture-related features will affect the outcome of the consumer's adoption decision.

Regarding consumer-related features, it is known that heterogeneity among individuals influences adoption of innovation (Van den Bulte \& Stremersch, 2004). Individuals differ in their propensity to adopt innovations. Depending on the speed of adoption, individuals can be segmented into categories, ranging from "innovators" through "early adopters", "early majority", "late majority" to "laggards" (Rogers, 2003 [1962]). Tourism researchers may note some 
similarities with Plog's (1974) psychographic model of travel attitudes ranging from allocentric to psychocentric types, or Cohen's model (1972); some of the limitations of Plog's model might apply to the ideal-type distribution of innovation adopters as well (Litvin, 2006; Smith, 1990). All in all, it is typical for innovations, that initially, before the "critical mass" is reached, only a small and particular group of customers (the innovators) adopt them. These customers are often not located in the mainstream but at the fringes of markets; they are highly risk tolerant, tend to have higher social status and financial capabilities (Christensen, 1997). Only later on, when the social pressure to adopt rises, the late majorities and laggards also tend to adopt newly introduced products and services (Meade \& Islam, 2006). Some authors argue that this pattern might be observed with Airbnb as well (Guttentag, 2015), which however is not to allege that the adoption is once forever or even exclusive in the sense that it would substitute all competing products or offers.

In addition to individual dissimilarities, research reveals notable differences in adoption patterns across markets and cultures (Peres et al., 2010). Amongst others, country differences in wealth, access to mass media, the degree of power inequalities, cultural values such as collective orientation and openness for innovations or time-lags in product introduction exhibit influence on the diffusion pattern of innovations (Dwyer, Mesak, \& Hsu, 2005; Stremersch \& Tellis, 2004).

Adoption decisions are also influenced by product-related features as not only the absorptive capacity of the adopter as well as the power of persuasion of the innovation plays a role in the adoption decision (Volgger, 2017). The persuasive power and attractiveness of an innovation are driven by its perceived features, such as the relative advantage of the product or service, its complexity, its trialability and observability as well as its compatibility (Rogers, 2003 
[1962]). Compatibility refers to the possibility to fit the innovation into an existing economic, cultural, technological and political context (Frambach \& Schillewaert, 2002). The easier it is to embed a new product or service into one's value system as well as technological and social context, the lower is the perceived risk associated with the innovation in question (Herzenstein, Posavac, \& Brakus, 2007). Similarly, familiarity with new products and services impacts the willingness to adopt. Familiarity refers to the degree of knowledge of potential adopters regarding a product or product category (Josiassen, Lukas, \& Whitwell, 2008). Previous research indicates that familiarity can facilitate learning of new product knowledge and may foster positive evaluations (Artigas, Vilches-Montero, \& Yrigoyen, 2015); however, prior experience negatively influences the curiosity-effect (Martins \& Pliner, 2005).

\subsection{Suggested Particularities of Airbnb Visitors}

As has been discussed, product-related, consumer-related and market/culture-related features affect the probability that a new product or service is adopted. In the case of Airbnb, given the relative novelty of the offer, use and adoption can be treated as conceptually similar. Therefore, the question is which specific factors may help to differentiate Airbnb users, i.e. those who have adopted the new offer. Existing literature suggests a number of characteristics associated with Airbnb use that relate to the visitor or to the specific trip undertaken (or a combination of both). Similar constellations may be found in other tourism choice situations (Ferrante, Abbruzzo, \& De Cantis, 2017; Han, Hsu, \& Sheu, 2010). In the following, we will first discuss characteristics relating primarily to the specific trip (organised as destination experiences, spending behaviour, spatial distribution and social dynamics in the travel group) and then cover aspects relating to the visitor in question (sociocultural background). 
Destination experiences: Existing literature suggests that Airbnb delivers a tourism experience that differs from the traditional accommodation industry (Mody et al., 2017). Specific aspects of Airbnb users' destination experiences might relate to indicators such as their travel purpose, number of previous visits, length of stay and trip activities. Regarding travel purpose, Airbnb is primarily referred to as an accommodation provision channel mostly utilized by holiday makers with much less uptake by business travellers (Guttentag, 2015). Indeed, surveys among actual and potential Airbnb users indicate that they do not see Airbnb to be particularly suitable for business travellers (Panda et al., 2015; Varma et al., 2016). Moreover, substitution effect analyses reveal that hotels that cater to business travellers face a lower exposition to Airbnb competition (Zervas et al., 2016).

Previous research underscores the necessity to analyse whether Airbnb can contribute to attract visitors to a destination that would not otherwise have visited (Guttentag, 2015). This can have implications for an economic evaluation of Airbnb but similarly impacts on the type of visitor experience. Arguments both for Airbnb promoting first visits and for being more suitable for subsequent visits can be found. On the one hand, Airbnb could facilitate access to insiderexplanations about the destination, which is particularly precious in cases of low destination familiarity. In addition, Airbnb may boost first visits by reducing cost-barriers that previously hindered converting the willingness to visit into an actual visitation. On the other hand, visitors being at their first visit in a destination might prefer the safe option of staying in traditional accommodations.

Moreover, several researchers have argued that Airbnb users are driven by a willingness to have local-like experiences in the destination (Gansky, 2010; Guttentag, 2015; Sigala, 2017; Tussyadiah \& Pesonen, 2016), although recent research takes on more cautious tones (Guttentag 
et al., 2017). There is sometimes even a tendency to associate Airbnb users with an alleged category of "travellers" or "alternative tourists" interested in everyday, authentic experiences, and to differentiate them from (normal) "tourists" (Molz, 2013; Week, 2012). In this sense, Airbnb users could be similar to home-swappers, who are reported to be particularly interested in cultural and natural attractions (Forno \& Garibaldi, 2015). It is also of interest to explore whether and how such an alleged experience-seeking behaviour of Airbnb users, occasionally denominated as "localhood" (Wonderful Copenhagen, 2016), affects length of stay. Indeed, for several cities, Airbnb reports longer length of stay of its users in comparison to hotel guests (Airbnb, 2017b).

In addition, researchers argue that Airbnb brings visitors in close contact with local hosts, thus providing the basis for co-creative and authentic experiences (Camilleri \& Neuhofer, 2017; Heo, 2016) and for an exploration of the accommodations' neighbourhoods (Varma et al., 2016). The special "quality of interaction" with hosts and the "homely feelings" that come with such an experience may not only be among Airbnb's primary success factors (Heo, 2016; Liu \& Mattila, 2017), they may even constitute one of the most radically new and different experiential attributes. While it is not completely new in principle that there is a "requirement for guests to ask hosts for permission to buy" (Karlsson et al., 2017, 2), the fact that the permission to buy is less de-personalized and automatized as in the case of most traditional accommodation providers, emphasizes the host-guest relationship. The fact that requesting Airbnb guests depend - or at least used to depend, before the "instant booking" option was introduced - on a case-bycase and personal agreement with the hosts, adds further to making the interpersonal communication and trust between Airbnb hosts and guests a crucial element of the experience (Ert, Fleischer, \& Magen, 2016; Karlsson et al., 2017). This is also reflected in the content of 
reviews which frequently mention the quality of communication as particularly relevant (Bridges \& Vásquez, 2016).

Spending behaviour: As for other sectors of non-traditional accommodation provision, several authors see the appeal of Airbnb especially in the possibility to save costs compared to other accommodation types (Guttentag, 2015; Möhlmann, 2015; Pizam, 2014), and thus see Airbnb in direct competition with budget accommodation providers (Hajibaba \& Dolnicar, 2017; Zervas et al., 2016). Indeed, previous studies note that the average rate of Airbnb-delivered accommodations tend to be lower than the rate of comparable accommodations in traditional accommodation sectors (Guttentag, 2015) and point to economic savings as being the primary motivation of using Airbnb (Guttentag et al., 2017). Similarly, customer surveys conducted among Airbnb users indicate that users perceive Airbnb to be less costly than hotels (Varma et al., 2016). Interestingly, Airbnb argues that notwithstanding lower rates its guest would exhibit a higher total spending in a destination than other types of visitors (Lawler, 2012). Independent research confirms contradictory signals regarding the relevance of the price variable and point out that higher income brackets do show interest in Airbnb offerings (Tussyadiah \& Pesonen, 2016).

Spatial distribution: Though most analyses consider Airbnb to be mostly an urban phenomenon, along the line of the authenticity assumption, it is argued that Airbnb-provided accommodations are spatially more scattered into areas with lower tourism intensity and differ in distribution from traditional hotel accommodation supply (Guttentag, 2015). Other studies allege an uneven or centre-periphery structure in the spatial distribution of Airbnb listings (Dredge \& Gyimóthy, 2015; Gutiérrez, Garcia-Palomares, Romanillos, \& Salas-Olmedo, 2017), with a concentration of Airbnb offers in the city centres and their immediate surroundings. Overall, 
Airbnb offers tend to be closer to attraction points and to heavily visited areas, compared to hotel accommodations (Gutiérrez et al., 2017) and Airbnb users seem to be motivated by "location convenience" (Guttentag et al., 2017).

Social dynamics in the travel group: It is difficult to predict for which types of travel parties Airbnb is most appealing as it offers different types of accommodations, mostly entire apartments and houses, but also rooms and even shared rooms. Surveys indicate that Airbnb users consider the platform to be generally attractive for families (Varma et al., 2016). However, in some markets such as India, Airbnb is reported to be a more suitable option for groups of friends travelling together (Panda et al., 2015). Overall, however, research on travel parties that use Airbnb is relatively scant.

Sociocultural background: Visitors' sociocultural background is amongst others captured by indicators such as source market, age and familiarity. Previous research on home-swapping finds that the geography of tourism flows between home and destination countries differs significantly from traditional accommodation provision (Russo \& Quaglieri Domínguez, 2014). Research on Airbnb put forward the assumption that its users must be "technologically and financially savvy" (Varma et al., 2016, 230), because they are required to be able to use the internet and to possess credit cards. Other papers formulate similar hypotheses regarding internet-affinity and "digital capital” (Dredge \& Gyimóthy, 2015; Guttentag, 2015) or "hipster" and urban lifestyles of Airbnb users in general (Dredge \& Gyimóthy, 2015). Therefore, the familiarity with online services and the ability to master online platforms is likely to play a role in the adoption of Airbnb, as is curiosity. Some find that Airbnb is more attractive to either young or experienced travellers who prefer new experiences even at the cost of varying quality standards (Russo \& Quaglieri Domínguez, 2014; Tussyadiah \& Pesonen, 2016). 
Second, although rather cautiously, some authors allege inter-cultural and sub-regional differences in Airbnb use (Möhlmann, 2015; Panda et al., 2015; Russo \& Quaglieri Domínguez, 2014), listing varying degrees of confidence with alternative types of accommodation offers but also different levels of generalized, inter-personal trust ("trusting strangers") as major causes. Familiarity seems to be important, and can be developed on several layers of closeness to the specific offer: Familiarity with the internet, with online platforms and sharing economy offers (John, 2013; Möhlmann, 2015), and even more immediate experiences directly with Airbnb via prior use, might be among the strongest indicators of future Airbnb usage (Panda et al., 2015). In brief, prior experiences of online-based "sharing" may help to learn the "logics" (John, 2013) of this hybrid practice, thus remove anxieties and wet appetite for more.

\section{Method}

\subsection{Data}

The data for our analysis of differentiators between Airbnb users and Airbnb non-users in Western Australia was provided by the "International Visitor Survey" (IVS) as conducted by Tourism Research Australia (TRA), a public Australian agency dedicated to tourism intelligence. The IVS, each year, surveys approximately 40,000 international visitors aged 15 years and over at the moment of their departure (at the airport) from their short-term stay in Australia. Thus, it is a systematic and controlled sample-based survey. It provides the major data source for measuring and characterizing international tourism to Australia. The survey is conducted with CAPImethod (Computer Assisted Personal Interviewing), that is face-to-face interviewing with the help of a computer to guide interviewer and respondent, in four languages (English, Japanese, 
Mandarin, Korean). Since 2015, the comprehensive questionnaire comprises a question regarding the use of internet platforms to book accommodation in private homes or apartments and allows to specifically identify Airbnb users. ${ }^{1}$

Although it would have been possible to consider multiple "sharing economy" platforms, for two reasons it was deemed more useful to focus just on the Airbnb-related subset. First, it constitutes the biggest proportion of users of sharing economy platforms in Western Australia (according to the utilised dataset, making up for seven times the visitors of any other single platform); and second, limiting the analysis to just one platform avoided the necessity to account for a significant diversity across the platforms used for sharing accommodations in tourism, which ranges from the non-commercial Couchsurfing platform to more hybrid models such as indeed Airbnb (Heo, 2016; Molz, 2013). To avoid any incontrollable overlapping and to allow for a clear-cut comparison, cases linked to other private accommodation platforms have been completely eliminated from the dataset. Thus, the remaining Airbnb non-users in the dataset did not book any other online-platform supported private accommodation.

We considered data for those international visitors who visited Western Australia (WA) in $2015 .^{2}$ The $2015 \mathrm{WA}$-sample consisted of 5,619 international visitors. The dataset allowed us to identify those visitors who used the Airbnb platform to book at least one accommodation in Western Australia. According to the dataset, 156 visitors, i.e. $2.8 \%$ of surveyed international visitors in Western Australia, used the Airbnb platform in 2015. The Western Australian share is close to the overall share of Airbnb users among international visitors to the whole of Australia in $2015(3.0 \%)^{3}$

No specific indications regarding sample size in logistic regression have been developed so far (Peng, Lee, \& Ingersoll, 2002). However, generally for multivariate analyses, a minimum 
ratio of 10 observations per predictor variable should be obtained (Bentler \& Chou, 1987; Nunnally, 1967). This condition is satisfied by the analysis presented here.

\subsection{Logistic Regression and Model Building Strategy Applied}

The aim of this research is to explore influence factors that allow to distinguish Airbnb use from Airbnb non-use. In this type of analysis, the response variable is binary (yes/no), and hence logistic regression is more appropriate than ordinary least squares (OLS) regression (Hosmer \& Lemeshow, 2000). The basic logistic regression model allows to estimate the probability of a discrete response variable, and for the case of a single explanatory variable reads as:

$$
P\left(Y_{i}=1\right)=\frac{e^{\beta_{0}+\beta_{1} x}}{1+e^{\beta_{0}+\beta_{1} x}}
$$

The basic idea is to apply a logit transformation to this logistic regression model to obtain the properties of linear regression models, despite the lack of a continuous outcome variable (Hosmer \& Lemeshow, 2000):

$$
\operatorname{Logit}\left(P\left(Y_{i}\right)\right)=\ln \left(\frac{P\left(Y_{i}=1\right)}{1-P\left(Y_{i}=1\right)}\right)=\beta_{0}+\beta_{1} x
$$

Usually, the unknown regression parameters are estimated with the maximum likelihood method, in an iterative fashion (Schlesselman, 1982). 
Based on Hosmer and Lemeshow (2000), and using SPSS software for data analysis, we took the following steps in model building and variable selection: Initially, we selected the variables from the wide-ranging data set that had been indicated as potential discriminators from the above literature review. Bivariate analysis, such as Pearson's Chi-Squared testing, can be used as a first step (Hosmer \& Lemeshow, 2000). To avoid overfitting of the model we used a cut-off $p$-value of 0.05 . We tested for multicollinearity by using multicollinearity diagnostics from a standard regression analysis (Midi, Sarkar, \& Rana, 2010).

Subsequently, we fitted the multivariable logistic regression model for all variables found significant in the bivariate model that fulfilled the previously outlined assumptions. The importance of each independent variable included in the comprehensive preliminary model was tested by examining Wald Chi-square statistics (Hosmer \& Lemeshow, 2000). Based on forward and backward variable selection procedures, the preliminary model was reduced to a more parsimonious model. As a final step, we controlled whether statistically significant interactions could be detected.

A list of all independent variables is provided in Table 1. Note that a few independent variables were categorized for analysis to remove the impact of larger outliers in the skewed distributions. For example, number of previous visits, length of stay, travel party size and spending per person had a very small number of extremely high values that can exert high influence on logistic regression estimates. This potential was eliminated by four categories with approximately equal numbers of visitors. As a sensitivity test, analysis was repeated with different categorizations and by including the original variables as continuous variables (with and without Winsorizing large values of their respective distributions). Some categorical 
variables had categories with few responses in the questionnaire combined with other similar categories prior to analysis (see Table 1).

Finally, following Taplin (2016), results of the logistic regression are interpreted as multiplicative effect on the probabilities of a visitor using Airbnb. Although these multiplicative effects are mathematically applicable to odds rather than probabilities, Taplin (2016) suggested they apply to rare events where the probability is less than $20 \%$. As the proportion of Airbnb uses is low (only 2.8\%) in our sample, this simpler interpretation in terms of probabilities is accurate.

\section{Results}

\subsection{Bivariate Analysis}

Table 1 reports results of the bivariate analyses of the distributions of variables that, based on the above literature review, were deemed potentially discriminating between the groups of Airbnb users and Airbnb non-users. The numbers in each category suggest large variation in the types of visitors. However, 50\% are young (less than 35 years old), 50\% have visited at most once before, $56 \%$ are travelling unaccompanied, most engage in trip activities that are outdoor and naturerelated $(83 \%)$, visit attraction points $(72 \%)$, and participate in social activities $(97 \%)$ but they rarely engage in activities involving indigenous culture (16\%). Only $14 \%$ of visitors stay in outback locations and 23\% stay in regional areas. The table reports the percentage of visitors within each category that use Airbnb and, for each variable, the evidence ( $p$-value) that these percentages of visitors differ by category. 
Table 1: Distribution of potential predictor variables related to Airbnb usage in WA (2015)

\begin{tabular}{|c|c|c|c|c|}
\hline Variable & Categories & $n$ & $\operatorname{Airbnb}(\%)^{\mathbf{b}}$ & $p$-value ${ }^{c}$ \\
\hline \multirow[t]{7}{*}{ Country of residence } & UK & 1,029 & 1.8 & $<0.001$ \\
\hline & Other Europe & 1,088 & 3.4 & \\
\hline & USA, Canada & 439 & 1.8 & \\
\hline & Singapore, Malaysia & 1,062 & 7.0 & \\
\hline & China & 238 & 1.7 & \\
\hline & Other Asia (incl. NZ) & 1,455 & 0.5 & \\
\hline & Others & 308 & 2.3 & \\
\hline \multirow[t]{3}{*}{ Age group } & Young (15 to 34 ) & 2,800 & 3.6 & $<0.001$ \\
\hline & Middle (35 to 54$)$ & 1,472 & 2.5 & \\
\hline & Old (55 upwards) & 1,347 & 1.4 & \\
\hline \multirow[t]{4}{*}{ Number of previous visits } & 0 & 1,766 & 3.9 & 0.003 \\
\hline & 1 & 1,019 & 2.9 & \\
\hline & $2-4$ & 1,361 & 2.4 & \\
\hline & $5+$ & 1,473 & 1.8 & \\
\hline \multirow[t]{4}{*}{ Nights (length of stay) } & $1-7$ & 1,928 & 3.8 & 0.001 \\
\hline & $8-14$ & 1,065 & 2.9 & \\
\hline & $15-28$ & 903 & 1.6 & \\
\hline & $29+$ & 1,723 & 2.1 & \\
\hline \multirow[t]{3}{*}{ Trip purpose (main) $^{\mathrm{e}}$} & Holiday & 1,960 & 5.4 & $<0.001$ \\
\hline & VFR & 1,964 & 1.1 & \\
\hline & Business, education, other & 1,695 & 1.7 & \\
\hline \multirow[t]{4}{*}{ Travel party type } & Unaccompanied & 3,171 & 1.5 & $<0.001$ \\
\hline & Couple, family & 1,731 & 4.7 & \\
\hline & Group of friends/relatives & 511 & 4.9 & \\
\hline & Business/school group & 206 & 1.5 & \\
\hline \multirow[t]{4}{*}{ Travel party size } & 1 & 3,171 & 1.5 & $<0.001$ \\
\hline & 2 & 1,714 & 4.1 & \\
\hline & $3-5$ & 532 & 5.6 & \\
\hline & $6+$ & 202 & 5.0 & \\
\hline \multirow[t]{2}{*}{ Trip activities: Outdoor, nature } & NO & 931 & 0.8 & $<0.001$ \\
\hline & YES & 4,688 & 3.2 & \\
\hline \multirow[t]{2}{*}{ Trip activities: Attraction points } & NO & 1,547 & 0.8 & $<0.001$ \\
\hline & YES & 4,072 & 3.5 & \\
\hline \multirow[t]{2}{*}{ Trip activities: Arts, heritage } & NO & 2,680 & 2.1 & 0.005 \\
\hline & YES & 2,939 & 3.4 & \\
\hline \multirow[t]{2}{*}{ Trip activities: Social, other } & NO & 149 & 0.7 & 0.113 \\
\hline & YES & 5,470 & 2.8 & \\
\hline \multirow[t]{2}{*}{ Trip activities: Sports } & $\mathrm{NO}$ & 3,258 & 2.7 & 0.570 \\
\hline & YES & 2,361 & 2.9 & \\
\hline \multirow[t]{2}{*}{ Trip Activities: Indigenous culture } & NO & 4,725 & 2.8 & 0.793 \\
\hline & YES & 894 & 2.9 & \\
\hline \multirow[t]{2}{*}{ Location of stay: City center (CBD) ${ }^{d}$} & NO & 3,019 & 2.6 & 0.267 \\
\hline & YES & 2,600 & 3.0 & \\
\hline \multirow[t]{2}{*}{ Location of stay: City suburbs $^{e}$} & NO & 2,933 & 2.8 & 0.926 \\
\hline & YES & 2,686 & 2.8 & \\
\hline Location of stay: Regions ${ }^{\mathrm{f}}$ & NO & 4,331 & 1.9 & $<0.001$ \\
\hline
\end{tabular}




\begin{tabular}{|c|c|c|c|c|}
\hline & YES & 1,288 & 5.7 & \\
\hline \multirow[t]{2}{*}{ Location of stay: Outback ${ }^{\mathrm{f}}$} & $\mathrm{NO}$ & 4,828 & 2.9 & \multirow[t]{2}{*}{0.164} \\
\hline & YES & 791 & 2.0 & \\
\hline \multirow{2}{*}{ Spending p.p. (A\$, excl. major transport) } & $\$ 500-\$ 1,500$ & 1,666 & 3.4 & \multirow{2}{*}{0.289} \\
\hline & $\$ 1,500-\$ 4,000$ & 1,217 & 2.5 & \\
\hline Total & & 5,619 & 2.8 & \\
\hline
\end{tabular}

Note: $n=5,619$

${ }^{b}$ Note: Provided figures under Airbnb usage are the percentage of visitors using Airbnb.

'Note: Pearson's Chi-Square test for independence, bold $p$-values indicate the test statistic is significant at $p<0.05$

dNote: "Business, education, other" includes the categories "convention/conference", "business", "employment", "education", "exhibition" and the remainder category "other purposes"

"Note: "Inner city" includes only the "City of Perth", "City suburbs" includes the "Experience Perth" region (excl.

City of Perth), "Regions" includes "Australia's South West" and "Coral Coast" regions, "Outback" includes

"Australia's North West" and "Golden Outback" regions

The results of the bivariate analysis indicate that for several potential predictor variables, the proportion of those who used Airbnb to book an accommodation for their stay in WA differs significantly from the average. Above average proportions might suggest associations of these variables with Airbnb usage. For instance, some source countries such as Singapore and Malaysia have a significantly higher share of Airbnb users; vice versa, other Asian countries (including New Zealand, excluding China), have a much lower share of Airbnb users. With respect to age, the relative proportion of Airbnb-users in WA is shifted towards younger age groups. In addition, having less often visited WA previously or staying shorter in WA increase the probability of resorting to Airbnb. The same holds for trip purpose: Being on holiday makes it relatively more likely to use Airbnb in comparison to other trip purposes. Moreover, different travel parties exhibit significantly different proportions of Airbnb users and Airbnb non-users. People travelling in bigger groups or in family contexts tend to be more often Airbnb users. It should be noted here that the IVS data collection is designed to prevent multiple members of the same travel party from completing the survey, thus avoiding a structural bias in this regard. 
International visitors who use Airbnb engage more often in certain activities during their trips. They participate significantly more often in outdoor and nature-related and arts and heritage-related activities. In addition, they visit tourism attraction points more often than Airbnb non-users. Although similar tendencies can be observed regarding social activities (e.g. visiting pubs, going shopping), they do not appear to be statistically significant at the $p$-value level of 0.05 .

In terms of location of stay, Airbnb users have a higher propensity to stay in the semiperipheral regions of WA compared to Airbnb non-users. In comparison, a stay in Perth's city centre, in Perth's suburbs or in the more peripheral regions (outback) does not seem to be relatively more likely with Airbnb users.

\subsection{Multivariable Analysis}

Those variables that were found to show statistically significant heterogeneity between Airbnb users and Airbnb non-users in the above bivariate analyses, were considered as candidates for inclusion into a multivariable (binary) logistic regression analysis. Before, this set of candidate variables was scrutinized for multicollinearity.

Condition indices, variance proportions, and variance inflation factors (VIFs) were used to examine multicollinearity issues. As a rule of thumb, condition indices that exceed 15 should be examined, if greater than 30 they indicate serious multicollinearity issues (Midi, Sarkar, and Rana 2010). If considering all variables from Table 1, the two variables "Location of stay: City Centre" and "Location of stay: City suburbs" showed a consistent structural relationship in the sense that most visitors stay in one or the other area but very rarely book accommodations in 
both. However, among the variables that showed to be significant in the bivariate analysis (see Table 1), the maximum condition index encountered amounted to 14.6; in addition, all these explanatory variables had VIFs below the critical value of 2.5 (Allison, 2001; Midi et al., 2010). Therefore, no further variables needed to be removed.

Please note that results of the logistic regression analysis are reported in log odds (B), odds (Exp. (B)) and probabilities. In general, odds are similar, but not equal to probabilities. However, for low values (up to 0.2), differences are minor and the odds approximate probabilities sufficiently well (Taplin, 2016). In this paper, the overall probability of a visitor using Airbnb is below 3\%, so as suggested by Taplin (2016), Exp.(B) coefficients are interpreted multiplicatively as changes in probabilities.

\subsubsection{Preliminary Model with all Potential Variables}

The model parameter estimates reported in Table 2 were produced by utilizing all variables significantly related to Airbnb usage (Table 1).

Table 2: Preliminary, extensive logistic regression model explaining Airbnb participation in WA $(2015)^{\mathrm{a}, \mathrm{b}, \mathrm{c}}$

\begin{tabular}{lccccc}
\hline Variable & Est. B & SE & Wald & $\boldsymbol{p}$-value & Exp. (B) \\
\hline Constant & -4.893 & 0.552 & 78.708 & $<\mathbf{0 . 0 0 1}$ & 0.006 \\
Country (overall) & & & 44.642 & $<\mathbf{0 . 0 0 1}$ & \\
$\quad$ Country (Other Europe) & 0.172 & 0.302 & 0.324 & 0.569 & 1.187 \\
$\quad$ Country (USA, CAN) & -0.052 & 0.436 & 0.014 & 0.905 & 0.949 \\
Country (Singapore, Malaysia) & 1.136 & 0.300 & 14.387 & $<\mathbf{0 . 0 0 1}$ & 3.115 \\
Country (China) & -0.276 & 0.574 & 0.231 & 0.631 & 0.759 \\
Country (Other Asia, incl. NZ) & -1.184 & 0.454 & 6.798 & $\mathbf{0 . 0 0 9}$ & 0.306 \\
Country (Others) & 0.337 & 0.461 & 0.534 & 0.465 & 1.401
\end{tabular}




\begin{tabular}{|c|c|c|c|c|c|}
\hline Age group (overall) & & & 8.570 & 0.014 & \\
\hline Age group (35 to 54 ) & -0.439 & 0.220 & 3.987 & 0.046 & 0.645 \\
\hline Age group (55 upwards) & -0.733 & 0.282 & 6.748 & 0.009 & 0.480 \\
\hline Number of prev. visits (overall) & & & 2.804 & 0.423 & \\
\hline Number of prev. visits (1) & -0.278 & 0.233 & 1.431 & 0.232 & 0.757 \\
\hline Number of prev. visits $(2-4)$ & -0.324 & 0.241 & 1.799 & 0.180 & 0.723 \\
\hline Number of prev. visits $(5+)$ & -0.343 & 0.274 & 1.559 & 0.212 & 0.710 \\
\hline Nights (overall) & & & 6.149 & 0.105 & \\
\hline Nights (8-14) & -0.339 & 0.237 & 2.038 & 0.153 & 0.713 \\
\hline Nights (15-28) & -0.723 & 0.332 & 4.737 & 0.030 & 0.458 \\
\hline Nights $(29+)$ & -0.468 & 0.257 & 3.318 & 0.069 & 0.626 \\
\hline Trip purpose (overall) & & & 8.332 & 0.016 & \\
\hline Trip purpose $(V F R)$ & -0.747 & 0.261 & 8.203 & 0.004 & 0.474 \\
\hline Trip purpose (Business, educ., other) & -0.104 & 0.261 & 0.158 & 0.691 & 0.902 \\
\hline Party type (overall) & & & 4.796 & 0.187 & \\
\hline Party type (couple, family group) & 0.769 & 0.424 & 3.299 & 0.069 & 2.158 \\
\hline Party type ( $g r$. of friends) & 0.498 & 0.429 & 1.347 & 0.246 & 1.645 \\
\hline Party type (business, school gr.) & -0.267 & 0.652 & 0.167 & 0.683 & 0.766 \\
\hline Party size $\left(\right.$ overall) ${ }^{\mathrm{d}}$ & & & 0.027 & 0.986 & \\
\hline Party size (2) & 0.061 & 0.388 & 0.024 & 0.876 & 1.062 \\
\hline Party size (3-5) & 0.038 & 0.406 & 0.009 & 0.925 & 1.039 \\
\hline Activity Outdoor, nature & 0.678 & 0.425 & 2.544 & 0.111 & 1.970 \\
\hline Activity Attraction points & 0.775 & 0.334 & 5.397 & 0.020 & 2.171 \\
\hline Activity Arts, heritage & 0.062 & 0.187 & 0.110 & 0.740 & 1.064 \\
\hline Location Regions & 0.901 & 0.186 & 23.492 & $<0.001$ & 2.462 \\
\hline \multicolumn{6}{|l|}{ Model Summary } \\
\hline Chi-Square & 236.321 & & & $<0.001$ & \\
\hline Nagelkerke Pseudo $\mathrm{R}^{2}$ & 0.184 & & & & \\
\hline
\end{tabular}

\footnotetext{
${ }^{\text {a} N o t e: ~ B o l d ~} p$-values are significant at $p \leq 0.05$
}

"Note: The baseline is "UK" for Country, "15-34" for Age group, “0” for Number of previous visits, "Holiday" for Trip purpose, "unaccompanied" for Party type and " 1 " for Party size.

Note: $\mathrm{n}=5,619$

${ }^{\mathrm{d}}$ Note: Party size (6+) dummy variable removed due to redundancy (Party size of " 1 " is equivalent to Party type of unaccompanied).

The visitors' source country, age, trip purpose, trip activities (attraction points) and location of stay (in semi-peripheral regions) are significantly associated with the probability of utilizing Airbnb while staying in Western Australia. ${ }^{4}$ The remaining variables are insignificant after adjusting for these and all other variables. Note that travel party type and travel party size are 
structurally related, with travel party equal to unaccompanied corresponding to a party size of 1 , forcing the removal of one dummy variable for party size in this multiple regression. While these results give an indication of which variables are significantly related to Airbnb after controlling for all other variables (while the bivariate results in section 4.1 give results adjusting for no other variables), the next section provides results for a parsimonious model.

\subsubsection{Parsimonious Model}

To achieve a more parsimonious model, stepwise regression was performed. Both forward and backward regression resulted in the same final model (Table 3). Following this model, it can be argued that the probability of being an Airbnb user in WA depends significantly and contemporaneously on (1) the source country of visitors, (2) their age, (3) their trip purpose, (4) the travel party type, the visitors' participation in (5) selected activities (tourism attraction points) as well as their (6) locations of stay (regions). Of the variables omitted from this parsimonious model, "Nights (length of stay)" ( $p$-value $=0.091)$ and "Trip activities: Outdoor, nature" $(p$-value $=0.107)$ were the closest to significance. There was minimal drop in model fit with the extensive model in the previous section, with the Nagelkerke pseudo $R^{2}$ reducing slightly (from 0.184 to 0.174 ). However, the parsimonious model appears to perform well in ranking respondents regarding their likelihood of using Airbnb and comparing this list with actual usage, as the measure of association Somer's D achieved a value of 0.637 (out of a maximum of $100 \%)$.

Table 3: Final parsimonious logistic regression model explaining Airbnb participation in WA (2015) 


\begin{tabular}{|c|c|c|c|c|c|}
\hline & Est. B & SE & Wald & $p$-value & $\operatorname{Exp}(\mathrm{B})$ \\
\hline \multicolumn{6}{|l|}{ Independent variables } \\
\hline Constant & -4.735 & 0.419 & 127.964 & $<0.001$ & 0.009 \\
\hline Country (overall) & & & 58.346 & $<0.001$ & \\
\hline Country (Other Europe) & 0.148 & 0.299 & 0.243 & 0.622 & 1.159 \\
\hline Country (USA, CAN) & 0.042 & 0.434 & 0.009 & 0.923 & 1.043 \\
\hline Country (Singapore, Malaysia) & 1.172 & 0.274 & 18.251 & $<0.001$ & 3.228 \\
\hline Country (China) & -0.243 & 0.571 & 0.182 & 0.670 & 0.784 \\
\hline Country (Other Asia, incl. NZ) & -1.219 & 0.450 & 7.320 & 0.007 & 0.296 \\
\hline Country (Others) & 0.390 & 0.458 & 0.723 & 0.395 & 1.476 \\
\hline Age group (overall) & & & 11.735 & 0.003 & \\
\hline Age group (35 to 54 ) & -0.454 & 0.210 & 4.697 & 0.030 & 0.635 \\
\hline Age group (55 upwards) & -0.851 & 0.274 & 9.655 & 0.002 & 0.427 \\
\hline Trip purpose (overall) & & & 13.942 & 0.001 & \\
\hline Trip purpose $(V F R)$ & -0.932 & 0.253 & 13.528 & $<0.001$ & 0.394 \\
\hline Trip purpose (Business, educ., other) & -0.352 & 0.241 & 2.142 & 0.143 & 0.703 \\
\hline Party type (overall) & & & 17.592 & 0.001 & \\
\hline Party type (couple, family group) & 0.851 & 0.207 & 16.823 & $<0.001$ & 2.342 \\
\hline Party type ( $g r$. of friends) & 0.614 & 0.269 & 5.203 & 0.023 & 1.848 \\
\hline Party type (business, school gr.) & -0.078 & 0.614 & 0.016 & 0.899 & 0.925 \\
\hline Activity Attraction points & 0.948 & 0.314 & 9.102 & 0.003 & 2.581 \\
\hline Location Regions & 0.786 & 0.179 & 19.355 & $<0.001$ & 2.194 \\
\hline \multicolumn{6}{|l|}{ Model Summary } \\
\hline Chi-Square & 223.455 & & & $<0.001$ & \\
\hline Nagelkerke Pseudo $\mathrm{R}^{2}$ & 0.174 & & & & \\
\hline
\end{tabular}

${ }^{\mathrm{a}}$ Note: Bold $p$-values are significant at $p \leq 0.05$

"Note: The baseline is "UK" for Country, "15-34" for Age group, "Holiday" for Trip purpose and "unaccompanied" for Party type.

${ }^{\mathrm{c}}$ Note: $\mathrm{n}=5,619$

The final parsimonious model indicates that visitors from certain source markets are significantly more likely to use Airbnb than others. For instance, as indicated by the exponentiated regression estimates B (last column in Table 3), the probability of visitors from Singapore and Malaysia booking accommodation in WA through Airbnb are 3.2 times higher than for UK visitors (baseline). In contrast, visitors from Asian source markets other than Singapore, Malaysia and China (but including visitors from New Zealand) are significantly less 
likely to use Airbnb in WA than UK visitors; visitors from the UK are $3.4(=1 / 0.296)$ times more likely to book Airbnb accommodation in WA than visitors from these "Other Asian countries".

Moreover, the model shows that younger age groups are more likely to use Airbnb in Western Australia. Visitors less than 35 years old are $1.6(=1 / 0.635)$ times more likely to book Airbnb in WA than visitors 35 to 54 and $2.3(=1 / 0.427)$ times more likely than visitors over 54 years old. Similarly, trip purpose impacts on the likelihood to use Airbnb for booking of accommodations in WA. Holidaymakers are $2.5(=1 / 0.394)$ times more likely to book accommodation through Airbnb compared to visitors travelling to WA for VFR reasons. In addition, the probability of Airbnb usage is 2.3 times higher for couples and family travel groups (and 1.8 times higher for visitors traveling in groups of friends) than single travellers.

Activity-related and location-related variables are influential predictors of Airbnb usage. International guests to WA who visit tourism attraction points are 2.6 times more likely to use Airbnb. To be clear, this is not reducible of having a holiday-related trip purpose; whereas about $35 \%$ of Airbnb visitors in the dataset declare a main trip purpose "holiday", around $72 \%$ visit attraction points. In addition, across every single category of trip purpose, including VFR, business and education, the share of those who visited attraction points is higher among Airbnb users than among Airbnb non-users. With regard to location of stay, visitors staying (also) in the semi-peripheral regions of WA are 2.2 times more likely to use the Airbnb-platform than those that do not stay in these areas.

Number of previous visits, travel party size and spending per person were all insignificantly related to Airbnb usage regardless of their measurement (e.g. Winsorizing) and no significant interaction effects were found. 


\section{Discussion}

First, international Airbnb users in Western Australia differ in their realized destination experiences. Obtained results highlight that use of Airbnb is strongly driven by trip purpose. As has been previously suggested (Guttentag, 2015; Panda et al., 2015; Varma et al., 2016), holidaymakers are significantly more likely to use the Airbnb platform than visitors with other trip purposes. However, in times when trip purposes become increasingly hybrid, a trip activities-related indicator such as whether a visitor visited tourism attraction points may be a similarly strong predictor of probability in Airbnb usage. This is in conformity with the above analysis.

Second, in contrast, trip activities other than "visitation to tourism attraction points" proved to be less clear-cut predictors of Airbnb usage in the analysed destination. Therefore, in spite of some indications from the bivariate analysis, this study cannot purport with confidence that interest in local culture or nature is a relevant predictor of Airbnb use. In addition to a significantly higher propensity of Airbnb users to visit tourism attraction points, this finding somewhat contradicts the idea that Airbnb is most appealing to a particular type of visitor sometimes described as "alternative tourist", or "traveller", in contrast to a type of behaviour coined as "mainstream" or "mass tourism" (Molz, 2013; Week, 2012). Based on this analysis, Airbnb visitors do not seem to be "alternative tourists" in the above logic, except in the sense of being interested tourists. They seem to have a genuine interest in the icons of the destination and have a tendency to visit more tourism highlights. Airbnb users may have some commonalities with locals in terms of board and lodging, but their trip activities seem to be first and foremost those of (curious) mainstream tourists. 
Third, many authors conceive Airbnb usage to be linked to price-reasons (Guttentag, 2015; Guttentag et al., 2017; Möhlmann, 2015; Pizam, 2014). While the analysis cannot rule out the argument that Airbnb usage in WA is strongly driven by economic reasons (such as saving money on accommodation), the above analysis does indicate that overall spending behaviour is not clearly reduced for Airbnb users. Although tendencies towards a somewhat reduced spending were observed from the bivariate analysis, the inferential results do not suggest overall spending behaviour to be a major differentiator between those international visitors that use Airbnb and those that do not. Unfortunately, the IVS dataset for 2015 used in this study does not contain information on household income, which might have helped shed further light on the role of economic indicators as differentiating variables of Airbnb users.

Fourth, the literature to date has remained relatively silent silent about travel parties that use Airbnb. In contrast, this study finds travel party type to be a relevant determinant of Airbnb usage. Specifically, using Airbnb seems to be particularly attractive to visitors who do not travel alone. For instance, couples or family groups are significantly more likely to book accommodations through Airbnb than unaccompanied visitors. This indicates that social and interactional aspects are drivers of Airbnb use, but it may not only concern the vaunted interaction between the travel group and residents (hosts and guests) but might also relate to social dynamics within the travel group. Moreover, the finding that larger groups are more likely to use Airbnb supports the argument that practical advantages play an important role in attracting visitors to using the platform (Guttentag et al., 2017). Essentially, a hotel room might be less suitable in satisfying some essential needs of extended travel groups than the prevailing types of Airbnb accommodations. 
Fifth, previous studies report a concentration of Airbnb supply in city centres (Dredge \& Gyimóthy, 2015; Gutiérrez et al., 2017). While not denying this supply-side oriented claim, the study results highlight a need for differentiation: Airbnb use does not appear to be a phenomenon limited to "city only" visitors. Indeed, among the discriminating categories regarding Airbnb use or non-use in WA are stays in semi-peripheral tourism regions such as "Australia's South West" or the "Coral Coast" tourism regions. ${ }^{5}$ To mirror the above argument of Airbnb users as curious tourists, these are appealing places for those who would like to discover the hinterland of WA, without needing to go too far from the capital city of Perth.

Beyond that, the strong link between Airbnb use and a stay in semi-peripheral regions (first of all, the Margaret River region) is puzzling. The type of supply might play a role as these regions offer a high share of holiday homes relative to standard hotels suitable for being transformed into Airbnb accommodations (Selwood \& Tonts, 2004). Parallels in type of consumers attracted might play a role as well (Pip Close, CEO MRBTA, personal communication). Australia's South West, and particularly the Margaret River region, might be described as chique and boutique tourism destinations but not yet overly famous in an international context. The observed fit between Airbnb users and the Margaret River region's positioning can be read on the one hand as an indication for Airbnb users to be exploring holidaymakers. However, this might on the other hand also indicate that Airbnb users in WA are not necessarily the very "early adopters" at the extreme discovery end of the market, but that the Airbnb phenomenon increasingly captures more average and mainstream market segments, falling more and more into the subgroup of early but not too early innovation adopters known as “early majority” (Rogers, 2003 [1962]). 
Sixth, previous research argued that flows between source and destination countries might differ on the grounds of accommodation type (Russo \& Quaglieri Domínguez, 2014). Profound investigations are lacking, but it is conceivable that cultural factors as well as some sort of internet-affinity and "digital capital" could play a role (Dredge \& Gyimóthy, 2015; Guttentag, 2015). The study reported in this paper reveals visitors' source country to be a highly relevant predictor of Airbnb usage. It can be observed that most traditional source countries for WA visitors such as the UK or New Zealand do not show a particularly high propensity to rely on Airbnb to book accommodations in WA. Interestingly, the same holds true for visitors from the more recently developing or recently developed countries from Asia, such as Indonesia, India but partly also China. From a historical perspective, these are somewhat less well-established visitor groups in WA. In contrast, the study's findings indicate the highest probability of Airbnb usage in WA for visitors from Singapore and Malaysia. At least two potential interpretations can be offered to help explain the phenomenon of a comparatively high likelihood of Malaysian and Singaporean visitors to use Airbnb in WA. A first interpretation points to the role of internet affinity. Both are countries with a relatively high internet speed and internet penetration rate (Akamai, 2016; Internet World Stats, 2017), which might indicate a considerable familiarity with the use of the online platform. Similarly, the study's finding that younger and middle-aged visitors are more inclined to use Airbnb might underscore the role familiarity and affinity with online services plays in the adoption of Airbnb. An alternative interpretation of Malaysians and Singaporeans using Airbnb in high numbers might refer to the markets' relative maturity in visiting WA, referring to what could be termed the markets" "visitation lifecycle". Singapore and Malaysia can be considered to be intermediately mature source markets for WA, with a considerable degree of tacit and in-depth knowledge about the destination combined with still 
adaptable travel patterns. This interpretation partly parallels the reading with respect to innovation adoption; in both perspectives, not the extreme ends of the markets, i.e. the very early adopting visitors or the most "alternative tourists", seem to constitute the key group of Airbnb users in WA; rather, Airbnb users among WA visitors appear to penetrate the mainstream and be part of a group that could be termed "innovative mainstream".

For destinations, the fact that Airbnb users differ from other tourists can constitute an opportunity for diversification of their guest base in general and the geographical distribution of their guests in particular. The different geographical distribution of Airbnb usage in comparison to traditional accommodation usage can have different reasons, but might, in particular in the studied destination, indicate that traditional tourism accommodation has not always been positioned in the most attractive places. With the help of Airbnb, guests can now more easily find accommodation opportunities close to some of the natural and cultural attractors of the destination. This can also be interpreted as a signal of a somehow reduced tourism planning and governance capability of traditional destination actors through the advent of Airbnb. The strong share of Airbnb users in some markets, in comparison to others, is a finding that should inform country-specific marketing initiatives. However, the finding that Airbnb users are penetrating towards the mainstream indicates that they may not require a completely different marketing than traditional accommodation users; according to the findings depicting Airbnb users as curious and active tourists they might be susceptible to destination-based marketing initiatives and 'hungry' for information on tourism activities and attraction points.

Hotels and traditional accommodation providers can learn that Airbnb seems to be particularly attractive for family groups and larger groups of people, maybe pointing to a structural weakness in some of their offerings for those target groups. The study findings signal 
to traditional accommodation providers and in particular hotels that in the competition with Airbnb their strongholds are business travellers and people travelling alone. However, to better tackle the "Airbnb segment", traditional providers should make sure they provide destination based product linkages, information and offerings.

The study's findings finally mean for Airbnb that its marketing should be well aware of catering to the mainstream and that their target audience has "grown up". Although polarising may be effective in branding, it could be advisable to watch some of the most trenchant messages in Airbnb's campaigns that point first of all towards being an alternative to ordinary tourism (see e.g. Roderick, 2016). The study findings might also indicate to Airbnb that social experience and enjoyment of community within the travel group are experiential components of paramount importance to many Airbnb users and could become even stronger key messages for future campaigns. The recent focus of Airbnb on families as a key target group (Ghosh, 2016) is supported by the findings of this study.

\section{Conclusion}

This paper positioned itself in the consumption and innovation research streams of the sharing economy literature (Cheng, 2016) and questioned if and what differentiates those who adopt the Airbnb-innovation from those who do not. A response to this question was achieved by systematically and rigorously comparing actual trip behaviour of Airbnb users with Airbnb nonusers from a sample of 5,619 international visitors to Western Australia in 2015. Due to this controlled comparison, the paper is the first one to offer a robust profiling of Airbnb users. 
In general, the study confirms the assumption of differences for the analysed destination from a demand-side perspective: International visitors to WA that use Airbnb differ on several trip-, person- and culture/market-related features from Airbnb non-users. The results of the logistic regression indicate that visitors' trip purpose, source country, age, travel party type, trip activities and the spatial distribution of the booked accommodation(s) (i.e. where visitors stay) are variables that impact strongly on the probability of international visitors using the Airbnb platform.

However, Airbnb adopters were not found to be an (extremely) "alternative" travel group, in the sense of, for example, being overly interested in local or indigenous culture, seeking radically new experiences or strictly avoiding traditional tourism attraction points. This paper therefore joins the warning voiced recently by Guttentag et al. (2017) regarding exaggerating experiential interpretations of the Airbnb phenomenon. The study drew a picture of an Airbnb user that is a curious visitor, but whose curiosity seems focused on exploring wellknown, iconic tourism highlights of the destination. In addition, the study did not find clear evidence that Airbnb users' spending is significantly less pronounced than the spending of Airbnb non-users. Therefore, the study results provide some indications that "[t]he collaborative phenomenon may be a hipster (rather than survival) phenomenon: driven and benefitted by people with high cultural, digital and networking capital” (Dredge \& Gyimóthy, 2015, 296). Moreover, it appears that the adoption of Airbnb usage for visitation to WA in the year 2015 extends into the progressive mainstream market, covering broad segments of tourism behaviour of what Cohen (1972) termed both "exploring" and "individual mass tourism".

By confirming the "difference hypothesis" and robustly characterizing Airbnb users in a specific destination, the study contributes to better understand users of the online platform of 
Airbnb and to inform marketing and management of destinations and businesses with respect to this visitor segment. In addition, from a theoretical perspective, the study responds to the call for cross-cultural comparison from Cheng (2016) and adds to the innovation adoption literature by suggesting notable cross-cultural differences in demand-side adoption of the innovation of Airbnb in particular and the sharing economy in general. Both an investigation of the reasons for these cross-cultural variations in adoption as well as the monitoring of its dynamic development are promising avenues for further research.

While the study indicates that Airbnb users differ from Airbnb non-users, it has not been designed to clarify from an economic point of view to what degree this "difference" involves substitution or complementation, and to what degree the adoption of the Airbnb platform creates exclusive use situations (in contrast to combined use with other online platforms). Therefore, it is an important avenue for further study to clarify whether Airbnb users would have visited the destination in case of this type of accommodation offer being absent. While the focus of this research was on adoption on the demand side, future research might also include supply side considerations such as the degree of price competition or even scrutinize adoption of the platform on the supply side. Additional limitations of the study relate to a focus on a single year for a single, although geographically extensive destination. Finally, the comprehensiveness of the used International Visitor Survey in Australia allows for a wide-ranging comparison of revealed travel behaviour, but has some shortcomings in a detailed analysis of motivations and previous experiences. Indeed, the use of such a standardised data set has its limitations due to the fact that it is not specifically designed to cover the peculiarities of Airbnb usage and its idiosyncratic aspects. Moreover, the IVS data set does not cover the decision-making process and thus does not allow investigation of substitution or complementation effects. For 2015, it also lacks 
information on household income. Therefore, a potentially important economic determinant of Airbnb user could not be fully explored.

\section{Endnotes}

${ }^{1}$ The question was asked as: 'Did you book any accommodation in a private home or apartment for this visit using one or more of the following websites? Interviewer note: We do not mean general online accommodation websites like WOTIF, Bookings.com, Hotelscombined.com etc. or the accommodation's own website." [A list of accommodation websites follows, including Airbnb]. Copies of the full questionnaire are available from the authors on request.

${ }^{2}$ This selection does not preclude that these visitors during their trips stayed also in other Australian states.

${ }^{3}$ To ensure a solid interpretation of data in a destination-based quantitative study, we only used Western Australian data although data for the whole of Australia was available. We focused on the subset, because an in-depth understanding of the destination in question helps to reduce risks of mistakes in data processing and interpretation, in particular when detailed location-based data needs to be dealt with.

${ }^{4}$ As suggested by a reviewer and by Tussyadiah and Pesonen (2016), for test purposes, we created a variable indicating the number of different activities undertaken during the trip. In a bivariate analysis, Airbnb use was indeed significantly associated with an increasing range of trip activities. However, when including this variable in the multiple regression, it lost its statistical significance, possibly due to its correlation with length of stay, and did not change our proposed model. 
${ }^{5}$ It should be noted that many international visitors to WA undertake multi-destination trips (54\% stay at least in two different places, and $41 \%$ in at least three different places). However, the available data does not allow to exactly identify in which part of their trip they utilized Airbnb-booked accommodations (it allows to specify that it was within WA).

\section{References}

Airbnb (2017a). About us. Retrieved from http://airbnb.com/about/about-us

Airbnb (2017b). Airbnb economic impact. Retrieved from http://blog.atairbnb.com/economicimpact-airbnb/

Airbnb Citizen (2017). Airbnb's 2016 highlights and 2017 trends we're watching. Retrieved from https://www.airbnbcitizen.com/airbnbs-2016-highlights-and-2017-trends-were-watching/

Akamai (2016). State of the internet: Connectivity report. Retrieved from https://www.akamai.com/us/en/our-thinking/state-of-the-internet-report/index.jsp

Allison, P.D. (2001). Logistic regression using the SAS system: Theory and applications. Cary: SAS Institute Inc.

Artigas, E.M., Vilches-Montero, S. \& Yrigoyen, C.C. (2015). Antecedents of tourism destination reputation: The mediating role of familiarity. Journal of Retailing and Consumer Services, 26, $147-152$.

Belk, R. (2014). You are what you can access: Sharing and collaborative consumption online. Journal of Business Research, 67(8), 1595-1600. 
Bentler, P.M., \& Chou, C.P. (1987). Practical issues in structural modeling. Sociological Methods \& Research, 16, 78-117.

Bridges, J., \& Vásquez, C. (2016). If nearly all Airbnb reviews are positive, does that make them meaningless?. Current Issues in Tourism, 1-19. doi:10.1080/13683500.2016.1267113

Camilleri, J., \& Neuhofer, B. (2017). Value co-creation and co-destruction in the Airbnb sharing economy. International Journal of Contemporary Hospitality Management, 29(9), 2322-2340.

Cheng, M. (2016). Sharing economy: A review and agenda for future research. International Journal of Hospitality Management, 57, 60-70.

Christensen, C.M. (1997). The innovator's dilemma. Boston: Harvard Business School Press.

Christensen, C.M. (2006). The ongoing process of building a theory of disruption. Journal of Product Innovation Management, 23(1), 39-55.

Cohen, E. (1972). Toward a sociology of international tourism. Social Research, 39(1), 164-182.

Cox, M. (2016). Inside Airbnb: Paris. Retrieved from http://insideairbnb.com/paris/

Dredge, D., \& Gyimóthy, S. (2015). The collaborative economy and tourism: Critical perspectives, questionable claims and silenced voices. Tourism Recreation Research, 40(3), 286302.

Dwyer, S., Mesak, H., \& Hsu, M. (2005). An exploratory examination of the influence of national culture on cross-national product diffusion. Journal of International Marketing, 13(2), 1-27. 
Ert, E., Fleischer, A., \& Magen, N. (2016). Trust and reputation in the sharing economy: The role of personal photos in Airbnb. Tourism Management, 55, 62-73.

Fang, B., Ye, Q., \& Law, R. (2016). Effect of sharing economy on tourism industry employment. Annals of Tourism Research, 57, 264-267.

Ferrante, M., Abbruzzo, A., \& De Cantis, S. (2017). Graphical models for estimating network determinants of multi-destination trips in Sicily. Tourism Management Perspectives, 22, 109119.

Forno, F., \& Garibaldi, R. (2015). Sharing economy in travel and tourism: The case of homeswapping in Italy. Journal of Quality Assurance in Hospitality \& Tourism, 16(2), 202-220.

Frambach, R.T., \& Schillewaert, N. (2002). Organizational innovation adoption: A multi-level framework of determinants and opportunities for future research. Journal of Business Research, 55(2), 163-176.

Gansky, L. (2010). The mesh: Why the future of business is sharing. New York: Penguin Books.

Ghosh, S. (2016, April 19). Airbnb targets families for the first time with 'Live There' campaign, campaign. Retrieved from https://www.campaignlive.co.uk/article/airbnb-targets-families-firsttime-live-there-campaign/1391792

Gutiérrez, J., Garcia-Palomares, J.C., Romanillos, G., \& Salas-Olmedo, M.H. (2017). The eruption of Airbnb in tourist cities: Comparing spatial patterns of hotels and peer-to-peer accommodation in Barcelona. Tourism Management, 62, 278-291. 
Guttentag, D.A. (2015). Airbnb: Disruptive innovation and the rise of an informal tourism accommodation sector. Current Issues in Tourism, 18(12), 1192-1217.

Guttentag, D., Smith, S., Potwarka, L., \& Havitz, M. (2017). Why tourists choose Airbnb: A motivation-based segmentation study. Journal of Travel Research, 1-18. doi:

$10.1177 / 0047287517696980$

Guttentag, D.A., \& Smith, S.L.J. (2017). Assessing Airbnb as a disruptive innovation relative to hotels: Substitution and comparative performance expectations. International Journal of Hospitality Management, 64, 1-10. doi: 10.1016/j.ijhm.2017.02.003

Hajibaba, H., \& Dolnicar, S. (2017). Substitutable by peer-to-peer accommodation networks?. Annals of Tourism Research, 66, 185-188.

Han, H., Hsu, L.T.J., \& Sheu, C. (2010). Application of the theory of planned behavior to green hotel choice: Testing the effect of environmental friendly activities. Tourism Management, 31(3), 325-334.

Heo, C.Y. (2016). Sharing economy and prospects in tourism research. Annals of Tourism Research, 58(C), 166-170.

Herzenstein, M., Posavac, S.S., \& Brakus, J.J. (2007). Adoption of new and really new products: The effects of self-regulation systems and risk salience. Journal of Marketing Research, 44(2), $251-260$.

Hosmer, D.W., \& Lemeshow, S. (2000). Applied logistic regression (2nd ed). New York: John Wiley \& Sons. 
Internet World Stats (2017). Internet usage in Asia. Retrieved from:

http://www.internetworldstats.com/

John, N.A. (2013). The social logics of sharing. The Communication Review, 16(3), 113-131.

Josiassen, A., Lukas, B.A., \& Whitwell, G.J. (2008). Country-of-origin contingencies:

Competing perspectives on product familiarity and product involvement. International Marketing Review, 25(4), 423-440.

Karlsson, L., Kemperman, A., \& Dolnicar, S. (2017). May I sleep in your bed? Getting permission to book. Annals of Tourism Research, 62, 1-12. doi: 10.1016/j.annals.2016.10.002

Koh, E., \& King, B. (2017). Accommodating the sharing revolution: A qualitative evaluation of the impact of Airbnb on Singapore's budget hotels. Tourism Recreation Research, 1-13. doi: $10.1080 / 02508281.2017 .1314413$

Lawler, R. (2012, November 9). Airbnb: Our guests stay longer and spend more than hotel guests, contributing \$56m to the San Francisco economy. TechCrunch. Retrieved from http://techcrunch.com/2012/11/09/airbnb-research-data-dump/

Litvin, S.W. (2006). Revisiting Plog's model of allocentricity and psychocentricity... one more time. Cornell Hotel and Restaurant Administration Quarterly, 47(3), 245-253.

Liu, S.Q., \& Mattila, A.S. (2017). Airbnb: Online targeted advertising, sense of power, and consumer decisions. International Journal of Hospitality Management, 60, 33-41. 
Martins, Y., \& Pliner, P. (2005). Human food choices: An examination of the factors underlying acceptance/rejection of novel and familiar animal and nonanimal foods. Appetite, 45(3), 214224.

Meade, N., \& Islam, T. (2006). Modelling and forecasting the diffusion of innovation-A 25-year review. International Journal of Forecasting, 22(3), 519-545.

Midi, H., Sarkar, S.K., \& Rana, S. (2010). Collinearity diagnostics of binary logistic regression model. Journal of Interdisciplinary Mathematics, 13(3), 253-267.

Mody, M.A., Suess, C., \& Lehto, X. (2017). The accommodation experiencescape: A comparative assessment of hotels and Airbnb. International Journal of Contemporary Hospitality Management, 29(9), 2377-2404.

Möhlmann, M. (2015). Collaborative consumption: Determinants of satisfaction and the likelihood of using a sharing economy option again. Journal of Consumer Behaviour, 14(3), 193-207.

Molz, J.G. (2013). Social networking technologies and the moral economy of alternative tourism: The case of couchsurfing.org. Annals of Tourism Research, 43, 210-230.

Nunnally, J.C. (1967). Psychometric theory. New York: McGraw-Hill.

Oskam, J., \& Boswijk, A. (2016). Airbnb: The future of networked hospitality businesses. Journal of Tourism Futures, 2(1), 22-42. 
Panda, R., Verma, S., \& Mehta, B. (2015). Emergence and acceptance of sharing economy in India: Understanding through the case of Airbnb. International Journal of Online Marketing, 5(3), 1-17.

Peng, C.Y.J., Lee, K.L., \& Ingersoll, G.M. (2002). An introduction to logistic regression analysis and reporting. The Journal of Educational Research, 96(1), 3-14.

Peres, R., Muller, E., \& Mahajan, V. (2010). Innovation diffusion and new product growth models: A critical review and research directions. International Journal of Research in Marketing, 27(2), 91-106.

Pizam, A. (2014). Peer-to-peer travel: Blessing or blight. International Journal of Hospitality Management, 38, 118-119.

Plog, S. (1974). Why destination areas rise and fall in popularity. The Cornell Hotel and Restaurant Administration Quarterly, 14(4), 55-58.

Poon, K.Y., \& Huang, W.J. (2017). Past experience, traveler personality, and tripographics on intention to use AirBnB. International Journal of Contemporary Hospitality Management, 29(9), $2425-2443$.

Rogers, E.M. (2003[1962]). Diffusion of innovations (5th ed). New York: Free Press.

Russo, A.P., \& Domínguez, A.Q. (2014). La lógica espacial del intercambio de casas: una aproximación a las nuevas geografías de lo cotidiano en el turismo contemporáneo [The spatial logic of house swapping]. Scripta Nova: Revista Electrónica de Geografía y Ciencias Sociales, 18(483). Retrieved from http://www.ub.es/geocrit/sn/sn-483.htm 
Schlesselman, J.J. (1982). Case control studies: Design, control, analysis. New York: Oxford University Press.

Schumpeter, J.A. (1942). Capitalism, socialism and democracy. New York, London: Harper.

Selwood, J., \& Tonts, M. (2004). Recreational second homes in the South West of Western Australia. In C.M. Hall \& D.K. Müller (Eds.), Tourism, mobility and second homes: Between elite landscape and common ground (pp. 149-61). Clevedon: Channel View Publications.

Roderick, L. (2016). Airbnb takes on mass tourism, with a "live there" campaign. Knowledge. Retrieved from https://ageofdesign.designweek.co.uk/airbnb-takes-on-mass-tourism-with-aimto-offer-complete-experiential-service-proposition/

Sigala, M. (2017). Collaborative commerce in tourism: Implications for research and industry. Current Issues in Tourism, 20(4), 346-355.

Slee, T. (2015). What's yours is mine: Against the sharing economy. New York, London: OR Books.

Smith, S.L.J. (1990). A test of Plog's allocentric/psychocentric model: Evidence from seven nations. Journal of Travel Research, 28(4), 40-42.

Stremersch, S., \& Tellis, G.J. (2004). Understanding and managing international growth of new products. International Journal of Research in Marketing, 21(4), 421-438.

STR (2017). Airbnb \& hotel performance: An analysis of proprietary data in 13 global markets. STR Report. Retrieved from http://www.str.com/Media/Default/Research/STR_AirbnbHotelPerformance.pdf 
Taplin, R.H. (2016). Research involving limited dependent variables: issues in the literature and recommendations for improvement. Quality \& Quantity, 50(5), 2121-2140.

Tussyadiah, I.P., \& Pesonen, J. (2016). Drivers and barriers of peer-to-peer accommodation stay-an exploratory study with American and Finnish travellers. Current Issues in Tourism, 118. doi: $10.1080 / 13683500.2016 .1141180$

Van den Bulte, C., \& Stremersch, S. (2004). Social contagion and income heterogeneity in new product diffusion: A meta-analytic test. Marketing Science, 23(4), 530-544.

Varma, A., Jukic, N., Pestek, A., Shultz, C.J., \& Nestorov, S. (2016). Airbnb: Exciting innovation or passing fad?. Tourism Management Perspectives, 20, 228-237.

Volgger, M. (2017). Umsetzungskompetenz als Erfolgsfaktor in Tourismusdestinationen [Implementation competence as a success factor in tourism destinations]. Wiesbaden: Springer.

Week, L. (2012). I am not a tourist: Aims and implications of 'traveling'. Tourist Studies, 12(2), 186-203.

Wonderful Copenhagen (2016). The end of tourism as we know it. Retrieved from http://localhood.wonderfulcopenhagen.dk/wonderful-copenhagen-strategy-2020.pdf

Xie, K.L., \& Kwok, L. (2017). The effects of Airbnb's price positioning on hotel performance. International Journal of Hospitality Management, 67, 174 -184.

Zervas, G., Proserpio, D., \& Byers, J.W. (2016). The rise of the sharing economy: Estimating the impact of Airbnb on the hotel industry (Working paper). Boston: Boston University. Retrieved from https://papers.ssrn.com/sol3/papers.cfm?abstract-id=2366898\#\# 